\title{
Referring cruise ship patients to specialists in Norway \\ - a welfare state with a national health care system
}

\section{Eilif Dahl}

Department of Occupational Medicine, Haukeland University Hospital, The Norwegian Centre for Maritime Medicine, Bergen, Norway

\begin{abstract}
Northern Europe is a popular cruise destination, but many non-Scandinavian cruise ship's doctors who are used to enthusiastic service from specialists ashore, get frustrated when referring passengers or crew to out-patient medical evaluation. Norway's national health care system is described and used as an example of medical conditions in a welfare state with a relatively well-functioning national health care system: Emergency cases are usually promptly admitted. Out-patient specialist consultations are available in public polyclinics, but waiting time can be considerable, also for patients from ships. Private specialists are fully booked weeks in advance and do not work from Friday to Monday and during holidays. Public and private medical service capacity is significantly reduced during the summer months. Hence, most specialists ashore are not eager to see demanding ship patients. Ship's doctors should limit referral to conditions that require specific procedures that are not available on the vessel but are necessary for the patient to be able to continue cruising or working aboard. Crewmembers who are unfit for work aboard, should instead be signed off and repatriated for diagnostic work-up and follow-up at home. In cases of hospitalisation or necessary referral ashore, the ship's doctor should always confer in advance with the company's ship's port agents and make necessary shore-side arrangements through them.
\end{abstract}

(Int Marit Health 2015; 66, 2: 67-71)

Key words: ship's doctor, specialist referral, hospitalisation ashore, ship's port agent, cruise medicine

\section{INTRODUCTION}

Cruise vessels are like moving cities with two distinctly different populations, passengers (often called guests) and crew. All cruise ships carrying 100 or more persons carry a doctor [1]. Most cruise lines operating along the Norwegian coast are members of the Cruise Lines International Association (CLIA) and their ships have medical facilities that can provide care according to - and even above and beyond CLIA minimum standards [2, 3]. Still, ship's doctors at times need to refer ill or injured passengers and crewmembers to specialist facilities ashore for procedures not available aboard. The cruise vessels contribute significantly to the economy of the ports of call, and in most ports around the world where medicine is a private enterprise, local clinics run by profit-making providers welcome and even aggressively compete to get patient referrals from visiting ships. This is not necessary the case in countries with national health systems, like Norway, and during the last years there has been complaints from ship's doctors that specialist referrals are difficult to get for patients from cruise vessels visiting northern Europe.

Based on personal experience and official reports, this article aims to provide some background information for non-Scandinavian ship's doctors who are unfamiliar with how health services in welfare states work, using Norway as an example. It might help them to manoeuvre within such a system when trying to get specialist care for their patients while cruising along the Norwegian coast. 


\section{NORWAY - THE CRUISE DESTINATION}

Promoted as "Land of the Midnight Sun", Norway is located in the northwestern corner of Europe. The world's second longest coastline (>100,000 km) offers more than 40 ports and destinations and rather spectacular nature with high, rugged mountainsides and long, narrow fjords. The climate is temperate along the coast, modified by the North Atlantic current, and during the summer months the nights are short and light. However, cruising is well on the way to becoming year-round tourism in Norway, which presently is the $4^{\text {th }}$ biggest cruise destination in Europe [4].

In 2013 there were 2,297 cruise ship calls in Norway, representing a total of 3.1 million day visits. Bergen, the second largest city of Norway and considered the country's cruise and maritime capital, had 329 ship visits, with a total of 475,000 guests [5]. Haukeland University Hospital in Bergen is the location of the Norwegian Centre for Maritime Medicine (NCMM) that operates the national telemedical advisory service for ships, 'Radio Medico' [6]. A negative factor for foreign tourists is generally high prices, which to some degree is compensated for by purchasing the cruise vacation at home.

\section{NORWAY - THE COUNTRY}

Norway's 5 million inhabitants are spread over nearly $400,000 \mathrm{~km}^{2}$, making it one of the most sparsely populated countries in Europe. It has enjoyed several decades of high growth, following the start of oil production in early 1970s, and is now one of the richest countries per head in the world. A politically stable social-democratic welfare state, Norway is divided into 3 different administrative levels: the state, the 19 counties and the 429 municipalities. The country is not a member of the European Union (EU), though it is a member of the European Economic Area (EEA), and it also retains close cooperation with the other Nordic countries [7].

\section{NORWAY - THE HEALTH CARE SYSTEM}

\section{ORGANISATION}

The Norwegian health care system appears to be high performing, and squarely turned towards delivering high-quality care [8]. The system has been developed as part of the welfare state after the Second World War to ensure that all inhabitants have access to high-quality care independently of where they live and of their socioeconomic status. The responsibility for specialist care lies with the state, which owns all but a few small hospitals. The municipalities are responsible for primary care, while the counties must provide statutory dental care [7].

The first contact with the health-care system is usually through the patient's regular, self-employed general practitioner (GP). There are also emergency centres in all municipalities with on-call physicians who serve as first contact physicians. Physicians in the municipalities (regular GPs and the on-call physicians in emergency centres) act as gatekeepers to more complex specialist care.

Out-patient specialist care is provided by the hospitals in their outpatient departments (called 'Akutt-mottak' or 'Poliklinikk') and also by self-employed privately practicing specialists (e.g. ophthalmologists, obstetricians, specialists in internal medicine, laboratory and radiology services, etc.), mostly working in their own practices under state contract.

In-patient specialised care is mainly provided by stateowned hospitals. In 2012, there were over 100 hospital facilities in Norway. Hospitals are mainly situated in urban areas but some smaller local hospitals are in remote areas. One hospital can cover a vast geographical area (e.g. in Nordland county, the distance between hospitals is more than $500 \mathrm{~km}$ ). Medical services of the highest complexity are provided in university (tertiary) hospitals [7].

All doctors in Norway speak (some) English, but many seem rather reluctant to write their reports in other languages than Norwegian.

\section{EMERGENCY SERVICES}

Everybody, regardless of citizenship or residency status, has access to acute emergency care, but note that only physicians or ambulance services can refer patients for emergency hospital consultation or for admission to hospital. In the case of medical emergencies (e.g. traffic accidents), patients may also be sent directly to the emergency department at the nearest hospital [7].

In urban areas there are designated emergency wards operated on a $24 / 7$ basis by the municipality. These are usually staffed with full-time physicians and nurses who provide advice, assess the situation and direct the patient to other types of care when needed. In all hospitals that provide emergency care there are accident and emergency departments, but patients are not allowed to seek treatment there directly. These departments usually have observational beds, where patients may be observed for several hours before being admitted to hospital or discharged, depending on their condition.

\section{AMBULANCE SERVICE}

A large network of ambulance transportation helps to counterbalance the geographical inequalities in Norway. The ultimate responsibility for ambulance services rests with the state and is provided by hospitals or by private sub-contractors. Highly specialised ambulances, including air ambulances, are staffed with physicians (mostly anaesthesiologists) in addition to emergency medical technicians [7]. Note that emergency medicine is not a certified medical specialty in Norway, Sweden, Denmark and Finland, but 
training in advanced out-of-hospital emergency medicine is traditionally attached to the specialty of anaesthesiology [9].

The government-owned company "Luftambulansetjenesten ANS" (National Air Ambulance Services of Norway) provides helicopter emergency medical service at 11 hospitals and dedicated fixed-wing aircrafts at 7 airports. The air ambulance helicopters operate $24 / 7$ and must be airborne within $15 \min [10,11]$. In addition the service depends on the state Search and Rescue helicopters operated from 6 military bases. Their primary function is search and rescue but hundreds of air ambulance missions are undertaken each year [7].

\section{ELECTIVE (NON-URGENT) CARE}

For elective specialised care, the regular GP either makes an appropriate appointment for the patient (e.g. with a private specialist who has an agreement with a hospital trust, a radiology centre or a hospital) or provides a referral so that the patient can arrange his or her own appointment.

Although Norway has one of the highest densities of physicians in Europe, the country struggles to assure geographical equity in access to health care. Also, despite extensive reforms, hospitals operate at their capacity limits; bed occupancy rate is high at 93\% (while the EU average is $76 \%$ ). This is reflected in long waiting times for elective care, a major cause of dissatisfaction among the patients [7]. According to a 2010 Organisation for Economic Cooperation and Development (OECD) survey, $50 \%$ of respondents in Norway had to wait more than 4 weeks for a specialist consultation, and $21 \%$ of respondents had to wait 4 months or more for elective surgery [12].

\section{PRIVATE HEALTH CARE PROVIDERS}

Several private actors are involved in the provision of health care services. Their involvement at the level of primary care is substantial: most GPs are self-employed but are in most cases fully embedded in the public system through contracts with the municipalities. In $2010,80 \%$ of GP referrals to radiology and $60 \%$ of GP referrals to laboratory services were made to for-profit facilities, but less than $2 \%$ of hospital beds are in private for-profit hospitals [12].

Dental care for adults (20 years and older) is the area of care with the highest private participation, both in terms of provision and financing. Most dentists work in private practices and most treatments are usually paid in full out of the patient's pocket. Fees are not regulated in the private sector [7].

\section{COVERAGE AND FINANCING}

Every person residing in Norway is entitled to publicly funded health care services. Public sources account for the majority (85\%) of health expenditure [7]. GP and outpatient specialist visits require flat fee co-payments as do physiotherapy visits, out-patient hospital care, and radiology and laboratory tests. All inpatient care in public hospitals or private hospitals contracted by the state, including day-care and same-day surgery in hospitals, is free of charge. However, dental care for adults is virtually excluded from coverage.

Residents from the EEA and EU have in principle the same entitlement to health services as Norwegians, and are reimbursed according to EEA regulations and bilateral agreements. Foreigners outside the EEA normally have to pay the full cost for services received. Foreign patients must, unless they come from other Nordic countries or hold a European Health Insurance Card (E-111), cover all treatment costs [7].

\section{NORWAY - BRIEFING NOTES FOR REFERRING SHIP'S DOCTORS}

\section{THE SHIP'S LOCAL PORT AGENTS}

In cases of referral or hospitalisation of passengers or crew, the ship's doctor should always confer in advance with the company's ship's agent of the port in question. Do it as soon as you become aware that a referral or hospitalisation might become necessary, and give the agent enough medical information to enable him or her to make the correct arrangements and avoid misunderstandings.

With current local knowledge of available medical and transport resources, the port agent can often give valuable advice on where to refer and provide pertinent phone numbers for direct contact with a port doctor or the doctors on duty at the local hospital. Keep in mind that most ship's agents have very little or no medical knowledge themselves, but need to have all relevant information when they consult with their medical contacts ashore.

\section{OUT-PATIENT OR SPECIALIST REFERRALS}

Ship's doctors should think twice about referring patients ashore for out-patient evaluations. As clarified below, it makes sense to only refer patients with conditions that require specific procedures or treatments that are not available on the vessel but need to be done in order for the patient to continue cruising - safely and in comfort. Good examples are referral to a dentist for a fractured, painful tooth, to an ophthalmologist to treat or rule out a detached retina and to an ultrasound examination to rule out an ectopic pregnancy. A crew member who is unfit for work doesn't need to be evaluated in port but should instead be signed off for diagnostic work-up and follow-up at home.

Ship patients with emergency conditions can be seen $24 / 7$ at the local hospitals emergency departments 
(“Akutt-mottak", "Poliklinikk"), but they must be prepared for waiting time. Patients are mostly seen on a "first come, first served' base, or - if obvious different degrees of urgency according to severity following triage. Patients from Norway and countries within the EU carrying the E-111 card will be charged according to EU rules, all others will be charged directly. Crewmembers are covered by the cruise company's insurance, except for most dental care.

Ship's doctors who are used to deal with mainly private, commercial health systems elsewhere might be surprised to learn that they are not considered doing doctors ashore in Norway "a favour" by referring ship patients to them. There are privately practicing medical specialist of various kinds in the larger cities, but most of them are fully booked for weeks ahead of time and ship referrals are disruptive and not popular. Fixed public salaries and more tax on high incomes do not motivate medical professionals to make extra efforts or to see more patients. Also, most private specialists do not work from Friday afternoon until Monday morning or during holidays. During the summer months both public and private medical services are markedly reduced as all Norwegians by law can take at least 3 weeks of their mandatory paid vacation during the summer months; hence, elective procedures are mostly postponed until the autumn.

Although consultations are expensive, and urgent ones even more so, most specialists have more than enough to do and are not eager to see demanding ship patients urgently, in particular for examinations or procedures thought to be non-urgent or elective. Hence, such patients are often treated accordingly; be prepared for passengers and crew not making it back on board before the ship leaves port, especially if several specialist have to be involved to properly examine and treat the patient.

On the other hand, fjord cruising means that the ship often passes the same area twice; in some areas the ship can drop a patient off in one area going into the fjord and getting him/her back on board when returning - or the patient might be able to join the ship in the next port a day or two later.

\section{HOSPITALISATION ASHORE}

Patients to be hospitalised are usually admitted rather promptly $24 / 7$, but will mostly be triaged at the emergency department prior to admission, in order to decide to which department the patient should be admitted - or to arrange for transfer to a larger hospital.

Transfers by ambulance or helicopters should be arranged through the ship's agent or (after initial hospitalisation) by the hospital.

\section{EMERGENCY NUMBERS}

While 911 is the well-known emergency telephone number intended for use in all kinds of emergency situations in North America, the number for EU countries is 112. In Norway there are 3 different emergency numbers: fire 110; police 112, and medical 113 , but if a medical emergency call is received at 112, it will be rerouted to 113 .

For medical emergencies on ships in port or near land, like in fjords: call 113 for medical advice and emergency transport to local hospitals [10].

For medical emergencies on ships at sea, call 'Radio Medico' directly (phone: +47 51683601; e-mail: advice@ radiomedico.no) or through 'Rogaland Radio' (phone: +47 51683600) 24/7 for emergency telemedical advice: All ships regardless of registry can contact 'Radio Medico' for free medical advice when at sea. Norwegian physicians connected to Haukeland University Hospital in Bergen are on call and communicate in English (or Norwegian on request) [6]. For further contact information, see: http://www.ncmm.no/about-radio-medico-norway/contact-radio-medico.

\section{PRE-CRUISING CONSIDERATIONS}

Passengers are strongly recommended to obtain travel insurance covering both medical attentions aboard and abroad, as well as repatriation. For safety reasons and to save time and money, passengers ought to be proactive and before leaving home ask their own physician for an English copy of their medical file, including a list of current medications and known allergies, as well as a copy of their most recent electrocardiogram. This information (together with their regular medication) should always be carried in their hand luggage and be presented to any doctor who needs to be consulted while away from home.

\section{POTENTIAL CONFLICT OF INTEREST/ADDITIONAL INFORMATION}

The author has worked in private general practice, municipal emergency departments and hospitals along the Norwegian coast and as a physician on cruise vessels all over the world, including Norway.

\section{REFERENCES}

1. Maritime Labour Convention 2006. Title 4 Regulation 4.1. http:// www.mlc2006.com/the_convention/title4/4_1 (Accessed 11 February 2015).

2. Cruise Lines International Association (CLIA). Policies. Medical facilities. http://www.cruising.org/regulatory/policies/medical-facilities (Accessed 09 February 2015).

3. American College of Emergency Physicians. Health Care Guidelines for Cruise Ship Medical Facilities; Revised July 2014. http://www. 
acep.org/Physician-Resources/Clinical/Health-Care-Guidelines-forCruise-Ship-Medical-Facilities (Accessed 09 February 2015).

4. Cruise Year 2013 - Press Release 10 October 2013 from Cruise Norway AS, Bergen. http://www.cruise-norway.no/viewfile. aspx?id=3864 (Accessed 15 January 2015).

5. Cruise Norway AS. Årsrapport 2013. http://www.cruise-norway.no/ viewfile.aspx?id=4146 (Accessed 15 January 2015).

6. The Norwegian Centre for Maritime Medicine. http://www.ncmm. no/about-radio-medico-norway/contact-radio-medico (Accessed 09 February 2015)

7. Ringard $\AA$, Sagan A, Sperre Saunes I, Lindahl AK. Norway: health system review. Health Systems in Transition 2013; 15: 1-162.

8. Organisation for Economic Cooperation and Development. OECD Reviews of Health Care Quality: Norway 2014: Raising Standards. OECD Publishing. http://dx.doi.org/10.1787/9789264208469-en
http://www.oecd.org/els/health-systems/ReviewofHealthCareQualityNORWAY_ExecutiveSummary.pdf (accessed 14 January 2015).

9. Langhelle A, Lossius HM, Silfvast T, Björnsson HM, Lippert FK, Ersson A, Søreide E. International EMS Systems: the Nordic countries. Resuscitation 2004; 61: 9-21.

10. Luftambulansetjenesten ANS. http://www.luftambulanse.no/National Air Ambulance Services of Norway http://www.luftambulanse. no/about-national-air-ambulance-services-norway (Accessed 11 February 2015).

11. Hovedredningssentralen. The Joint Rescue Coordination Centres http://www.hovedredningssentralen.no/english/index.asp (Accessed 11 February 2015).

12. Organisation for Economic Cooperation and Development. Health at a Glance: Europe 2012. OECD Publishing, Paris. http://dx.doi. org/10.1787/9789264183896-en. 